\title{
Política de combate à pobreza no Brasil, concepções e estratégias
}

\author{
Darana Carvalho de Azevedo \\ Universidade Federal Fluminense (UFF)
}

\author{
Luciene Burlandy \\ Universidade Federal Fluminense (UFF)
}

\section{Política de combate à pobreza no Brasil, concepções e estratégias}

Resumo: Este artigo aborda o debate em torno da política de combate à pobreza no Brasil, analisando as correlações entre concepções de pobreza e as intervenções adotadas. Para tanto, realiza um prelúdio das principais abordagens conceituais de pobreza e, à luz deste entendimento, problematiza de que forma as estratégias políticas implementadas no país afetam os múltiplos determinantes desse quadro. Neste propósito, destaca a discussão sobre a eficácia das estratégias universais e/ou focalizadas, demonstrando que as dificuldades em operacionalizar políticas pautadas numa compreensão de pobreza como um problema multidimensional fragilizam a consolidação de critérios de justiça social e desconsideram o potencial das políticas integradas para o alcance destes princípios.

Palavras-chave: pobreza, políticas sociais, intervenção.

\section{Anti-Poverty Policy in Brazil, Concepts and Strategies}

Abstract: This article concerns the debate about anti-poverty policy in Brazil and analyzes the relations between concepts of poverty and interventions adopted to address it. The article begins with a review of the principal conceptual approaches to poverty, based upon which it analyzes how policy strategies implemented in the country affect the multiple determinants of the situation. The paper is highlighted by a discussion of the effectiveness of universal and or focused strategies. It demonstrates that the difficulties in implementing policies based on an understanding of poverty as a multidimensional problem weaken the consolidation of criteria of social justice and disregard the potential for integrated policies to achieve these principles.

Key words: poverty, social policies, intervention. 


\section{Introdução}

Nas últimas décadas, fortalece-se no meio acadêmico o debate em torno dos tipos de proteção social que têm sido implementados em diferentes contextos. As principais críticas recaem sobre as intervenções específicas, pontuais e de curto prazo, focalizadas nos pobres visando alívio imediato da pobreza em detrimento de um sistema de defesa e garantia de direitos universais ou de políticas que conjugam ações focais e universais de médio e longo prazo.

Sem desconsiderar a relevância desta discussão, destaca-se que a preocupação em criticar ou reafirmar determinadas estratégias políticas não tem sido acompanhada de uma análise mais profunda sobre a adequação entre os tipos de intervenções e os determinantes da pobreza.

O presente artigo tem como objetivo analisar as relações entre as concepções de pobreza, que pautam os caminhos adotados, e os rumos que, aparentemente, a atual política de combate à pobreza no Brasil vem traçando. Indica a importância deste debate para uma análise mais contextualizada das intervenções focais e/ou universais, pois desconsiderar esses fatos pode comprometer a compreensão multidimensional da pobreza, além de mistificar o poder de justiça social dessas intervenções.

$\mathrm{O}$ texto parte de uma reflexão sucinta das diversas abordagens teórico-conceituais sobre pobreza a fim de analisar, num segundo momento, a atual política de combate à pobreza no Brasil, considerando as distintas concepções que balizam as ações neste campo. Por fim, problematiza a discussão em torno da universalização versus focalização dos programas, à luz do entendimento de pobreza como um problema complexo e multidimensional.

\section{Debate conceitual em torno da pobreza}

Conforme Rocha (2003, p. 9), "pobreza é um fenômeno complexo, podendo ser definido de forma genérica como a situação na qual as necessidades não são atendidas de forma adequada." Essa concepção nos leva a questionar quais são as necessidades e o que é adequado, indicando assim, que se trata de um fenômeno complexo, composto por dimensões subjetivas, econômicas, sociológicas e políticas que variam conforme as especificidades locais, em razão das heterogeneidades sociais e culturais.

Com efeito, trata-se de um conceito em construção, cujos pressupostos diferem de acordo com os valores e princípios sociais. Podendo ser, portanto, conceituada de diferentes maneiras, como é observado na literatura.

Dentre as concepções vigentes na literatura, há as que se estabelecem a partir da ênfase no caráter econômico da pobreza, generalizando uma abordagem que a define predominantemente como uma condição de "insuficiência de renda" (ATKINSON, 1989). Desta abordagem originam-se os conceitos de "pobreza absoluta" e de "pobreza relativa", sendo que o primeiro refere-se ao não atendimento das necessidades vinculadas ao mínimo vital, isto é, aos fatores necessários à sobrevivência física. E o segundo, como precisões a serem satisfeitas em função do modo de vida predominante na sociedade em questão, ou seja, trata-se de um conjunto de indivíduos relativamente pobres em sociedades que já garantiram o mínimo vital a todos.

Para Rocha (2003, p. 12), a renda como critério de pobreza é o estabelecimento de "um valor monetário associado ao custo do atendimento das necessidades médias de uma determinada população". A partir de valores distintos são estabelecidas as linhas de indigência e de pobreza. A primeira diz respeito, especificamente, às necessidades nutricionais e a segunda faz referência a um conjunto mais amplo das necessidades (habitação, vestuário, transporte etc.).

Na prática, a constituição destas linhas, a partir da noção de consumo mínimo necessário, apresenta algumas dificuldades: no que concerne à cesta básica alimentar o problema está em definir a composição da cesta e a escolha dos preços adequados por produto; já em relação às outras necessidades básicas não se dispõe de parâmetros de consumo essencial, neste caso, juízos de valores são inevitáveis.

Mediante esta situação Atkinson (1989 apud SANTOS, 2007, p. 19) declara:

Necessidades nutricionais dependem de onde as pessoas habitam e do que elas fazem. Elas variam de pessoa para pessoa, de forma que qualquer resultado será apenas probabilístico: para um certo nível de consumo há uma certa probabilidade de que a pessoa esteja inadequadamente alimentada.

Mesmo com todas estas implicações, dois fatores justificam a motivação pela abordagem de linhas de pobreza e indigência: primeiro, é que somente as medidas escalares permitem a ordenação de situações sociais alternativas; segundo, existe uma estreita correlação entre o nível de renda e os indicadores de bem-estar físico, uma vez que o acesso a bens e serviços se dá no mercado através de recursos monetários (ROCHA, 2003).

As linhas de pobreza e indigência também podem ser definidas próximas à noção de pobreza relativa, visto que, quanto mais rica a sociedade, mais o conceito de pobreza se distancia do atendimento das necessidades de sobrevivência. Entretanto, neste caso, as linhas de pobreza relativa estão estritamente imbricadas às questões de distribuição de renda em vez de estarem associadas ao valor de cestas de 
consumo como no primeiro exemplo. Porém, este tipo de análise gera índices não diretamente comparáveis. Mesmo ao se considerar um único país, as comparações intertemporais têm que ser vistas com cautela, pois, por ser definida de forma relativa, a renda dos pobres pode declinar sem que se caracterize aumento da incidência de pobreza.

Segundo Rocha (2003), os países pobres e de renda média têm feito uma aplicação indevida dessa abordagem de linha de pobreza relativa onde a noção de pobreza absoluta ainda é relevante. Sendo assim, Rocha (2003, p. 17) afirma que "Em países de renda média como o Brasil, com economia urbana e monetizada, mas onde persiste importante contingente populacional desprivilegiado, a abordagem de pobreza absoluta ainda é relevante."

No entanto, é preciso também levar em consideração, principalmente quando se refere a países pobres, a autoprodução e outros consumos não monetários. Esses fatores provocam impactos nas condições de vida das camadas mais pobres, podendo ser equivocadamente ignorados pelos pesquisadores por estarem dissociados do grau de sucesso da integração das famílias à economia de mercado, como prevê a utilização da renda como referência.

Embora a pobreza ainda seja avaliada predominantemente pelo critério da renda, existem outras concepções que reforçam a necessidade de inclusão de dimensões não econômicas na análise das condições de vida, sendo estas pautadas nas teorias das necessidades básicas e das capacitações. A abordagem das necessidades básicas determina que uma pessoa seja pobre se ela não consegue ter acesso a uma gama de "bens primários" que atenda às necessidades humanas elementares (SANTOS, 2007).

Adotar esta abordagem é ir além daquelas baseadas nas demandas alimentares, incorporando outras necessidades humanas, tais como educação, saneamento, habitação etc. É abandonar a renda como indicador-chave. É estabelecer objetivo e medir resultados para a sociedade, sem delimitação de uma subpopulação pobre, visando desenvolver instrumentos de análise que permitam estabelecer comparações entre os países e monitorar o desenvolvimento dos mesmos. É, também, dar ênfase ao caráter multidimensional da pobreza e ao reconhecimento da inter-relação entre as diversas carências.

Para Santos (2007), esta concepção de pobreza consiste em definir, de forma mais precisa, quais são as necessidades básicas de cada sociedade, considerando suas especificidades, já que estas variam de uma localidade para outra. Por exemplo, o acesso à rede de captação de esgoto sanitário em áreas urbanas densamente povoadas é essencial, mas desnecessário em áreas rurais, onde o uso da fossa séptica pode ser adequado.

A outra abordagem, conhecida como a das capacitações, considera a pobreza como privação decorrente de insuficiência de renda, mas acredita que apenas esse enfoque não dá conta de um grande número de outras realizações humanas, tornando a teoria muito distante da realidade. Contudo, não nega que a renda baixa é uma das causas principais da pobreza.

O que a diferencia das outras abordagens é o "espaço avaliatório", ou seja, a identificação de um conjunto de variáveis relevante para o bem-estar de uma pessoa. Logo, a avaliação da pobreza depende da seleção do espaço em que esta será apreciada, assim a ponderação das necessidades humanas tem de ajustar-se à existência de uma diversidade humana generalizada: seres humanos distintos ensejam necessidades e prioridades distintas.

Sen (2000) justifica as razões para as variações a partir de quatro pontos. Primeiro, a relação entre renda e capacidade seria acentuadamente afetada pela idade da pessoa (por exemplo, específicas do idoso), pelos papéis sociais e sexuais (obrigações familiares, responsabilidade com a maternidade), pela localização (propensão a inundações ou secas, violência etc.), pelas condições epidemiológicas e por outras variáveis sobre as quais a pessoa pode não ter controle ou ter um controle apenas limitado.

Como segundo ponto, haveria uma junção de desvantagens entre privação de renda e dificuldade na conversão de renda em funcionamentos ${ }^{1}$.

\begin{abstract}
Desvantagem como a idade, incapacidade ou doença reduzem o potencial do indivíduo para auferir renda. Mas também tornam mais difícil converter renda em capacidade, já que uma pessoa mais velha, mais incapacitada ou mais gravemente enferma pode necessitar de mais renda (para assistência, prótese, tratamento) para obter os mesmos funcionamentos (SEN, 2000, p. 110).
\end{abstract}

Assim, a pobreza real, em um sentido significativo, pode ser mais intensa do que aparenta quando avaliada apenas com base na renda.

$\mathrm{O}$ terceiro ponto diz respeito à distribuição dentro da família, apresentando complicações adicionais na abordagem da pobreza baseada na renda. Usada de forma desigual para alguns membros da família em detrimento de outros, o grau de privação de determinados integrantes da família pode não se refletir adequadamente pela renda familiar.

Já no quarto, a privação relativa de rendas pode resultar em privação absoluta de capacidades. De modo que, ser relativamente pobre em país rico pode ser uma grande desvantagem, pois as dificuldades que alguns grupos de pessoas enfrentam para se integrar à vida da comunidade podem ser cruciais na identificação da exclusão.

No entanto, cabe considerar também que os segmentos mais pobres em países com forte desigualdade 
de renda têm condições diferenciadas dos mesmos segmentos em países onde o contexto geral é de pobreza.

Sen (2000) acredita que maiores capacidades para viver a vida tendem a aumentar o potencial de uma pessoa para ser mais produtiva e auferir renda mais elevada. $\mathrm{O}$ aumento na capacidade conduz a uma elevação na disposição de angariar renda, e não ao contrário, contribuem para isso os serviços de saúde e educação básica. Porém, o autor adverte:

\section{É perigoso ver a pobreza segundo a perspectiva limitada da privação de renda e a partir daí justificar investimentos em educação, serviços de saúde etc. com o argumento de que são bons meios para atin- gir o fim da redução da pobreza de renda. Isso seria confundir os fins com os meios (SEN, 2000, p. 114).}

Esta abordagem considera que para a avaliação da pobreza é necessário o intercâmbio da economia com as demais esferas de pensamento como o direito, a filosofia, a sociologia, a política e até mesmo a biologia. Neste caso, as privações são vistas em um nível mais fundamental, introduzindo novas considerações éticas na avaliação do que realmente importa para o bem-estar de um indivíduo, tornando-se mais próximas de questões de justiça social.

Por ser complexa e multidimensional, esta interpretação da pobreza suscita questionamentos referentes a alguns pressupostos importantes que devem pautar a formulação de estratégias de combate à pobreza. O primeiro deles é a importância de um profundo conhecimento dos contextos locais, considerando que os determinantes da pobreza podem ser muito distintos, especialmente em países como o Brasil. Outra questão é a necessidade de uma abordagem integral do problema, ou seja, ações que afetem as múltiplas dimensões da pobreza e que sejam integradas e convergentes nos seus usuários potenciais, de forma a se adequarem às suas necessidades.

Com efeito, esta abordagem indica a necessidade da conjunção de diferentes tipos de ações e sua integração a uma política que considere intervenções de curto, médio e longo prazo.

\section{Política de combate à pobreza no Brasil}

No início do novo milênio, o combate à pobreza adquire proeminência e seu enfrentamento é redimensionado no cenário internacional. $\mathrm{O}$ Banco Mundial afirma que o combate a pobreza é um dos principais desafios mundiais, difundindo uma ideia de pobreza para além da baixa renda, incluindo também baixos indicadores em educação, saúde, nutrição e outras áreas do desenvolvimento humano (VAITSMAN; ANDRADE; FARIAS, 2009, UGÁ, 2004)
Com isso, novos argumentos sobre as relações entre pobreza e desenvolvimento afirmam-se, tendo como base a teoria das capacidades de Sen. Tal acontecimento desvela outras dimensões da pobreza agora enfatizadas para além da renda.

Entra em ascensão a opinião de que políticas e instituições voltadas para os grupos mais vulneráveis podem promover tanto eficiência quanto equidade. A partir de então, os programas de transferência com condicionalidades, focalizados nos pobres passam a ser implementados no intuito de cumprir funções redistributivas e de alívio da pobreza (VIANNA, 2008).

Com efeito, novas estratégias de proteção social emergem combinando redes de segurança, transferência de renda e focalização nos pobres para que sirvam de auxílio nos períodos de crise e de "trampolim” para a superação da situação de pobreza.

Diante destas novas concepções, várias questões entram em disputa em torno dos tipos de proteção que vêm sendo implementados: intervenções específicas, pontuais e de curto prazo, focalizadas nos pobres, em detrimento do que deveria ser um sistema de defesa e garantia de direitos universais.

No Brasil, esse debate entra no circuito acadêmico. Questionamentos referentes às estratégias políticas de combate à pobreza confrontam-se com uma realidade onde é confuso o entendimento que se tem de pobreza, e obscuro o rumo estratégico da política adotada. A pobreza enquanto "questão" assume maior relevância em meados da década de 1990, num contexto de estabilização monetária com o Plano Real, porém de restrição econômica para o social, devido aos ajustes neoliberais.

Este contexto, juntamente com as estratégias mundiais sugeridas para o combate à pobreza, vai favorecer a emergência de políticas focalizadas com maiores critérios de seletividade, com ênfase nas regiões mais pobres, priorizando territórios e segmentos da população com alta prevalência de pobreza. Consequentemente, essas ações, em sua maioria, vão apresentar como prioridade os critérios de renda.

Outro fator importante é o momento de redemocratização do país, com setores da sociedade civil mobilizados em torno da superação da pobreza, como a Ação da Cidadania contra a Fome, que culmina em 1993 com o surgimento do Conselho Nacional de Segurança Alimentar (Consea).

Em 1995, no Governo Fernando Henrique Cardoso, o Consea é dissolvido como parte de novas estratégias de enfrentamento à pobreza. É criado, então, o Comunidade Solidária que procurava articular, de forma descentralizada e através de parcerias com a sociedade civil, outros programas já existentes em diferentes ministérios para enfrentar a fome e a miséria. No entanto, estudos indicam que, apesar de favorecer a convergência de alguns programas setoriais para os municípios mais pobres, a integração 
destas ações no nível municipal e o alcance dos segmentos mais pobres nestes municípios foram frágeis (BURLANDY, 2003; VELLOZO, 2000).

No seu conjunto, a política de assistência social e de enfrentamento à pobreza ganha novos formatos e conteúdos ao longo da década de 1990, abrangendo uma gama ampla e diversificada de programas. Alguns universais e contínuos e outros emergenciais, focalizados e temporários dirigidos às diferentes situações de carência e vulnerabilidade social.

Dentre as inovações, destacam-se os programas de inserção produtiva voltados para os trabalhadores desempregados e os inseridos no mercado informal de trabalho. Sua principal representação encontrase no Plano Nacional de Educação Profissional (Planfor), iniciado em 1996, tem como objetivos qualificar a força de trabalho, elevar o nível de escolaridade da população economicamente ativa, estimular a oferta de emprego e de oportunidade de geração de renda, entre outros.

Também voltados para a melhora da renda e do emprego estão os novos programas de crédito popular como o Programa de Geração de Renda (Proger), iniciado em 1995, com iniciativas de apoio ao pequeno empreendimento. A partir deste, outros surgiram como o Proger Rural, o Programa Nacional de Apoio a Agricultura Familiar (Pronaf), o Programa de Crédito para a Reforma Agrária (Procera) e o Programa Crédito Produtivo Popular do BNDS. Contudo, vale destacar que há peculiaridades entre pobreza urbana e rural, visto que existem determinantes específicos para cada con-

texto como, por exemplo, o acesso à renda e a bens e serviços públicos, à terra e aos meios produtivos. Cabe considerar se os programas e as ações implementados nesta situação afetam de forma integrada estes múltiplos determinantes.

Ainda nessa década, surgem os programas de transferências condicionadas de renda que procuram garantir patamares mínimos de renda familiar, com objetivos de melhoria do desempenho escolar e da saúde dos sujeitos assistidos. Seguindo essa proposta, em 1996, o Governo Federal lança o Programa de Erradicação do Trabalho Infantil (PETI), com a finalidade de retirar crianças e adolescentes do trabalho precoce, combinando transferência de renda com a participação em uma jornada ampliada de estudos e atividades correlatas.

Em 2001, após a aprovação pelo Congresso Nacional do Fundo de Combate e Erradicação da Po- breza são lançados importantes programas federais de transferência de renda, por três diferentes ministérios: Bolsa Escola, do Ministério da Educação; Bolsa Alimentação, do Ministério da Saúde; Auxílio Gás, do Ministério de Minas e Energia. Em 2002, o Bolsa Escola alcança uma cobertura de cerca de cinco milhões de famílias, recorde naquele período.

$\mathrm{Na}$ esfera dos direitos assistenciais, o Benefício de Prestação Continuada (BPC) é o principal benefício implementado. Este prevê a transferência de um salário mínimo para idosos e deficientes que possuem uma renda familiar per capita inferior a $1 / 4$ do salário mínimo, sendo revisado a cada dois anos.

Em 2003, primeiro ano do governo Lula, o destaque é a unificação dos programas de transferência de renda federais no Programa Bolsa Família, o que viabilizou sua expansão nacional para alcançar todas as famílias abaixo da linha de pobreza estabelecida.

Seguindo este processo, entre 2000 e 2007, há um crescimento contínuo dos recursos executados nos programas de transferência de renda ${ }^{2}$. A execução orçamentária de 2007, em relação ao início do período, quase quadruplica ${ }^{3}$. Com isso, uma significativa parcela da população mais pobre e vulnerável é incorporada ao sistema de proteção e ao mercado de consumo popular (BARROS, 2000).

Porém, por si só a presença destes programas não é suficiente para afirmar que existe uma estratégia política de combate à miséria que abarque de forma integrada estas intervenções em função de objetivos mais amplos. Além disso, cabe avaliar se essas iniciativas estão realmente atingindo seus propósitos de inserção no mercado de trabalho, de maior autonomia dos segmentos assistidos e de promoção e garantia dos demais direitos.

É imprescindível, também, analisar sua articulação às demais políticas. Isto é, se a compreensão de pobreza que baliza as políticas públicas for multidimensional, é fundamental que as ações destinadas a enfrentá-la afetem seus múltiplos determinantes econômicos, sociais, culturais, entre outros. Se for esse o caminho, então estamos diante de ações contraditórias, como indicam os trabalhos realizados por Pochmann (2007) e Lavinas (2007). Segundo esses autores, no período referente a 2001-2004, houve uma redução do gasto federal em algumas funções necessárias para a diminuição efetiva da desigualdade, como educação, habitação e saneamento, em contraposição ao aumento dos programas de transferência de renda e aos gastos totais ${ }^{4}$. 
Imaginar que o problema da vulnerabilidade social e econômica seria solucionado simplesmente com programas pontuais e emergenciais revelaria uma compreensão equivocada do que é pobreza, discrepante da atual concepção que se busca adotar mundialmente.

Entender a pobreza como um problema multidimensional, condicionada por diversos determinantes para além dos exclusivamente econômicos, é considerar que serviços desmercantilizados como escola, creche, esgoto sanitário, água encanada, saúde são dimensões intrínsecas e primordiais de uma política de combate à pobreza.

Já no recente trabalho de Monteiro et al. (2009), observa-se, no período de 2005-2006, a ocorrência de investimentos crescentes nos serviços sociais básicos e universais, com maior relevância aos serviços de educação e saúde. Porém, tal pesquisa não revela se este aumento é compatível com os demais gastos sociais e se são eficazes, isto é, se afeta problemas de prevalência crescente.

Enfim, desde que este tema adquire relevância no Brasil, assiste-se a uma variação nos investimentos do governo para com o social, ora apresentando uma desarticulação entre eles e uma fragmentação desequilibrada de investimentos, ora apontando para uma integralidade das ações e dos gastos sociais.

Por esta razão, não fica claro se estamos caminhando para uma política de combate à pobreza, ou para um conjunto de estratégias pontuais e emergenciais de alívio à pobreza sem uma devida responsabilidade com as mudanças de médio ou longo prazo. As futuras ações apontarão a resposta.

Todavia, independentemente deste parecer, sobrevive o debate em torno da focalização. Vianna (2008) diz que a política de combate à pobreza no Brasil tem sido concebida de forma unânime como uma política social de compensação pelos prejuízos que a desigualdade causa a alguns, justificando, portanto, sua focalização nos pobres.

\section{Universalização versus focalização}

No atual governo, a política de combate à fome e à pobreza tem reforçado e dado continuidade aos Programas de Transferências Condicionadas de Renda. Tal fato tem levado alguns teóricos, como Mauriel (2006), a defender que o governo Lula, baseado nas teorias de Sen, tem utilizado um enfoque individualista. Segundo Mauriel (2006, p. 53) "[...] os esforços recentes têm sido direcionados para medir indicadores comportamentais, ou 'defasagens' de habilidades e/ou capacidades que devem ser supridas com treinamento educacional e cultural."

Esta autora afirma, ainda, que esta perspectiva não altera a estrutura, fazendo com que as políticas percam seu caráter redistributivo. E mais ainda, por levar em consideração as especificidades, as políticas locais são defendidas e funcionam para tornar mais eficiente o uso dos recursos. Para a autora, isso não resolve o problema, nem muda a ordem social estabelecida.

Porém, ao se remeter à concepção de pobreza defendida por Sen (2000), percebe-se que o alcance a um determinado patamar de condições de vida varia grandemente, segundo características fisiológicas, sociais e culturais, além de outras igualmente contingentes. Há uma série de fatores de ordem não econômica que influenciam, por exemplo, os serviços de educação e saúde, os direitos políticos e civis, a assistência social, a participação na comunidade, o respeito próprio, o capital social, o acesso ao crédito e à terra, o tipo de emprego (formal ou informal).

As capacitações, estando determinadas pelas disposições econômicas, sociais e políticas vigentes em uma sociedade, levam a conclusão de que o Estado e a sociedade são os maiores responsáveis pelo fortalecimento e pela proteção das capacitações humanas (SEN, 2000).

Com isto fica claro que não basta a supressão das faltas de capacidades por meios individualistas, mas sim por políticas amplas e intersetoriais que abranjem e afetem de forma convergente todos os condicionantes da pobreza em cada contexto específico. Não se trata, então, de promover apenas uma redistribuição de renda, ainda que seja essencial, mas de redefinir coletivamente valores e práticas sociais, bem como critérios de justiça social. Pois, segundo Sen (1990, p. 25) “o valor do padrão de vida repousa na vida, e não na possessão de mercadorias, a qual tem relevância derivada e variável."

O ponto chave não é de como surjem os meios para a conquista de qualidade de vida - se através de estratégias focalizadas ou universais - , mas sim qual a capacidade que estes possuem para exercerem efeitos sobre a pobreza.

Segundo Kerstenetzky (2006), uma política pode ser focal, mas possuir uma "concepção espessa de justiça social", ou até mesmo ser universal e possuir uma "concepção fina de justiça social" o que, consequentemente, altera o efeito previsto no combate à pobreza. Pois para a autora, justiça social é pensada como redistribuição de oportunidades de realização.

Ainda, de acordo com a autora, a concepção espessa de justiça, com ênfase na focalização, trata de ações redistributivas de recursos para geração de oportunidades sociais e econômicas para grupos em desvantagem. Sendo necessária para restituir a esses indivíduos o acesso efetivo a direitos universais: "Sem a ação/política/programa, focalizados nestes grupos, aqueles direitos são letra morta ou se cumpririam apenas num horizonte temporal muito distante" (KERSTENETZKY, 2006, p. 570). 
Essas ações complementariam políticas públicas universais, "corrigindo" injustiças passadas de desigualdades de recursos e capacidades. Necessárias principalmente em sociedades onde a pobreza é muito extensa, plural e estratificada como a nossa. Não obstante, para que as políticas se aproximem do ideal de direitos universais a algum nível decente de realização, a focalização seria um requisito para a universalização de direitos efetivos (KERSTENETZKY, 2006).

No entanto, uma política pode ser focal, mas com uma concepção fina de justiça que se refere a uma rede de proteção mínima/residual, que seria coerente com uma visão de justiça de mercado, ou seja, do neoliberalismo. Esta acepção possui uma visão moral entre os que merecem ou não o acesso às políticas. Aqui o imperativo de eficiência global supera o do direito e o da equidade, ou seja, é preciso buscar o foco correto para se atingir a solução de um problema.

Por outro lado, uma política pode ser universal, mas ter uma concepção fina de justiça social, de forma que também estaria associada à noção de justiça de mercado, desempenhando, assim, um desenho de seguridade social e educação básica, insuficientes para atingir a grande gama de necessidades dos despossuídos sociais e econômicos. Nesse caso, é como se fosse uma focalização para o setor inverso, sendo útil apenas aos que possuem melhores condições, facilitando-lhes o acesso via mercado às outras necessidades.

O que se busca alcançar, sem sombra de dúvidas, é uma universalização com concepção espessa de justiça social. Próxima ao que Esping-Andersen (1991) chamou de processo de "desmercantilização", ou seja, a atitude de elevar a responsabilidade pública acima da dinâmica mercadológica e da tradição familiar na provisão dos bens e serviços dos seus sistemas de proteção social. Para isto, é preciso ofertar uma larga quantidade de benefícios e serviços sociais visando uma qualidade de vida universal a todos os cidadãos, sem qualquer tipo de distinção.

Enfim, com base nesta leitura, pode-se considerar que é possível conciliar focalização (no sentido de redistribuição/reparação) e universalização na implementação de políticas pautadas nos critérios de justiça social, de forma que a combinação eficiente das duas possa abranger questões estruturais sem estar negligenciando questões emergenciais e urgentes, que também merecem atenção.

Além disso, compreender essas estratégias a partir de uma leitura de justiça social é conceber a pobreza como uma questão de caráter multidimensional cujos condicionantes são específicos de cada contexto. Portanto, para enfrentá-la são necessárias políticas que sejam capazes de afetar os diversos fatores e dimensões deste processo, de forma integrada e, mais ainda, que sejam adequadas as especificidades de cada contexto.

\section{Conclusão}

A literatura acadêmica oferece um vasto campo teórico de concepções de pobreza, fornecendo, desta forma, um arsenal de saberes e de conceitos que enfatizam o critério da renda para delimitar a pobreza, e outros que priorizam uma visão multidimensional da mesma.

Nas últimas décadas, este segundo tipo de abordagem vem pautando o debate acadêmico e a formulação de programas sociais no Brasil. Contudo, na prática o que se verifica é a implementação de ações que privilegiam a transferência e geração de renda, com desproporcional atenção dirigida para os serviços sociais. Desta forma, o conjunto de intervenções implementadas, por vezes de forma fragmentada, não consegue operacionalizar uma concepção ampliada de pobreza.

No entanto, recentemente, identificam-se esforços no sentido de equalizar os investimentos em ações no âmbito dos serviços básicos e universais, com ênfase para a saúde e a educação. Contudo, ainda, não se pode afirmar se isto constitui, de fato, uma política de combate à pobreza ou um conjunto de estratégias isoladas, implementadas de modo descontínuo em cada contexto governamental específico, sem uma clara preocupação com os resultados de médio e longo prazo.

Muitas questões ainda precisam ser equacionadas considerando-se o processo de implementação destas estratégias num contexto diverso como o brasileiro, tais como: os tipos de intervenções que vêm sendo formuladas e implementadas até então pelo Governo Federal são de fato as mais relevantes para cada contexto local específico? Afetam os múltiplos determinantes da pobreza? Há uma convergência desses programas, de forma a integrar as ações?

Estes questionamentos, a fim de prevenir intervenções utópicas e não funcionais, devem, também, estar conectados à realidade brasileira, na qual não existe o pleno emprego, onde as relações trabalhistas são precárias e diversos direitos não são plenamente garantidos.

Estas questões são importantes para a construção de uma política que seja capaz de considerar a pobreza em suas múltiplas dimensões: econômica, social, política, cultural, simbólica, subjetiva, dentre tantas outras. São, portanto, primordiais para a formulação de políticas públicas em um país como o Brasil, onde a pobreza não se constitui em razão da falta de recursos econômicos e sim da perversa desigualdade em sua distribuição. O que, com efeito, é reflexo e reflete as demais condições de vida e os valores sociais vigentes. Valores estes, que não são apenas mensurados, mas também, sentidos.

O elemento central de uma estratégia de combate à pobreza no contexto brasileiro deveria ser a bus- 
ca por uma maior liberdade/oportunidade de escolhas, tendo como referência não somente a desigualdade de renda e a dificuldade de acesso a bens e serviços em quantidade, qualidade e diversidade, mas também aos demais condicionantes aqui destacados. Nesse sentido, não é suficiente o investimento em políticas de geração, incentivo e/ou transferência de renda, ainda que fundamentais, sendo primordial que estas intervenções estejam integradas ao acesso aos demais serviços sociais e às políticas públicas.

Assim, o que realmente é vital para o combate à pobreza no Brasil é a formulação de políticas voltadas ao alcance da justiça social e o próprio questionamento dos valores sociais vigentes (como a discriminação por gênero, raça, etnia, nível socioeconomico, a aceitação das imensas desigualdades sociais, da concentração de renda, de salários, de acesso a bens e serviços), uma vez que eles contribuem para a perpetuação das desigualdades. A formulação de políticas desta ordem só é possível mediante um olhar multidimensional da pobreza e de processos políticos que promovam a integração de diferentes atores e ações que afetem os múltiplos determinantes deste quadro.

\section{Referências}

ATKINSON, A.B. Poverty. In: EATWELL, J.; MILGATE, M.; NEWMAN, P. (Ed.). Social Economics. New York: London, 1989.

BARROS, R. P. et al. Desigualdade e pobreza no Brasil: retrato de uma estabilidade inaceitável. Rio de Janeiro: IPEA, 2000.

BURLANDY, L. O. Comunidade solidária e os programas de alimentação e nutrição: focalização e parcerias. 2003. Tese (Doutorado em Saúde Pública) - Fundação Oswaldo Cruz. Rio de Janeiro, 2003.

ESPING-ANDERSEN, G. As três economias políticas do Welfare State. Lua Nova - Revista de Cultura e Política, São Paulo, n. 24, p. 85-116, 1991.

KERSTENETZKY, C. L. Políticas sociais: focalização ou universalização. Revista de Economia Política, São Paulo, v. 26, n. 4, p. 564-574, out./dez. 2006.

LAVINAS, L. Gasto social no Brasil: programas de transferência de renda versus investimento social. Revista Ciência e Saúde Coletiva, v. 12, n. 6, p. 1463-1476, 2007. Disponível em: <http:/ /www.scielo.br>. Acesso em: 11 fev. 2010.

MAURIEL, A. P. Combate a pobreza e (des)proteção social: dilemas teóricos das "novas" políticas sociais. Revista Praia Vermelha, Rio de Janeiro, v. 14, p. 48-71, 2006.
MONTEIRO, D. A. A. et al. Evolução dos gastos sociais e transferência de renda no Brasil: reflexões sobre o Programa Bolsa Família [on-line]. Brasília. Disponível em: <http://www.undp-povertycentre.org > Acesso em: $11 \mathrm{fev}$. 2010.

POCHMANN. M. Política social na periferia do capitalismo: a situação recente no Brasil. Revista Ciência e Saúde Coletiva, Rio de Janeiro, v. 12, n. 6, p. 1477-1489, 2007. Disponível em: <http://www.scielo.br>. Acesso em: 11 fev. 2010.

ROCHA, S. Pobreza no Brasil: afinal de que se trata? Rio de Janeiro: FGV, 2003.

SANTOS, L. M. N. Pobreza como privação de liberdade: um estudo de caso na favela do Vidigal no Rio de Janeiro. 191 p. Monografia (Conclusão de Pós-Graduação em Economia) - Universidade Federal Fluminense, Niterói, 2007.

SEN, A. The Standard of living. Cambridge: Cambridge University Press, 1990.

UGÁ, V. D. A categoria pobreza nas formulações de política social do Banco Mundial. Revista de Sociologia e Política, Curitiba, v. 23, p. 55-62, 2004. Disponível em: <http:// www.scielo.br>. Acesso em: 11 fev. 2010.

VAITSMAN, J.;ANDRADE, G R. B.; FARIAS, L. O. Proteção social no Brasil: o que mudou na assistência social após a Constituição de 1988. Revista Ciência e Saúde Coletiva, Rio de Janeiro, v.14, n. 3, p. 731-741, 2009. Disponível em: <http:/ /www.scielo.br>. Acesso em: 11 fev. 2010.

VELlOZO, V. Comunidade solidária: experiência (com)partilhada? 281p. Tese (Doutorado em Saúde Pública) - Escola Nacional de Saúde Pública, Fiocruz, Rio de Janeiro, 2000.

VIANNA, M. L. W. A nova política social no Brasil: uma prática acima de qualquer suspeita teórica? Revista Praia Vermelha, Rio de Janeiro, v. 18, n. 1, p. 120-145, 2008.

\section{Notas}

1 Funcionamentos são objetos de valor encontradas em múltiplas formas de "ser" "e "fazer", não se atendo ao universo do "ter" (SEN, 2000).

2 A partirde 2004, os programas: BolsaFamília, PETI, Benefício de Prestação Continuada e Agente Jovem ficam sob responsabilidade do Ministério de Desenvolvimento Social e Combate à Fome.

3 Para obter maiores informações ver Barros (2000). 
4 Pochmann(2007)alerta, também, paraumaumentona parcela de recursos destinados à área financeira para pagamento da dívida pública, sustentado pelo crescimento da carga tributária, especialmente pela ampliação das contribuições sociais, constitucionalmente previstas para financiar a Seguridade Social (previdência, saúde e assistência social). Isto é, investe-se em ações que provavelmente representam um empecilho para a redistribuição da renda e, consequentemente, para o enfrentamento do problema da desigualdade.

\section{Darana Carvalho de Azevedo}

darana_a@yahoo.com.br

Mestranda em Política Social pela Universidade

Federal Fluminense (UFF)

Orientadora: Profa. Dra. Luciene Burlandy

\section{Luciene Burlandy}

burlandy@uol.com.br

Doutora em Saúde Pública pela Fundação Oswaldo

Cruz

Professora adjunta na UFF

\section{UFF - Escola de Serviço Social}

Rua Professor Marcos Waldemar de Freitas Reis

Bloco $\mathrm{E}-3^{\circ}$ andar

Campus Universitário do Gragoatá,

São Domingos

Niterói - Rio de Janeiro

CEP: 24210-201 